\title{
The Analysis of Stone Trapping in Tire Tread for Various Road Conditions
}

\author{
Jun Yi Eugene Gow ${ }^{1}$ and Pei Xuan $\mathrm{Ku}^{1, *}$ \\ ${ }^{1}$ School of Computer Science and Engineering, Faculty of Innovation and Technology, Taylor's \\ University, 47500, Selangor, Malaysia
}

\begin{abstract}
A tire tends to trap stones in its tread pattern when the vehicle is on a move and this might affects the tire balance due to uneven tread wear of tread portion. The study aims to simulate stone trapping performance under various tire tread patterns and road conditions as well as assessing the performance of tires with stones trapped. The stone trapping phenomena on different tire tread pattern were analyzed under dry and wet road conditions. The tire models chosen were the symmetrical tire, asymmetrical tire, and directional tire. The model of these tires, stone and a flat road surface were created using SolidWorks and Fusion360 software and the static structural simulation is performed by using finite element analysis method. Tire inflation analysis and steady state rolling analysis were conducted to evaluate three parameters: total deformation, Von-Mises stress and equivalent elastic strain of the tires. It found that all three parameters are higher when stone trapped in tire for all tread pattern types. Symmetrical tread pattern provides the least wear and tear since it has the lowest increment of maximum equivalent elastic strain in both road conditions. Stone trapping in tire grooves would impact on the lifespan of the tire.
\end{abstract}

\section{Introduction}

The occurrence of stone trapping normally happens in a moving vehicle and it varies depending on the stone structure. When the vehicle is in a motion, the downward pressure exerted by the weight of the tire forces the stone to slide in between the grooves which then leads to stone trapping. Stone trapping could cause some of the harmful effect to the tire such as affecting the tire balance due to uneven tread wear of the tread portion. Another common issue would be the shorter lifespan of the tire which is caused by the tire damage after some period due to stone trapping. The type of tire damage includes cuts, impacts, cracks, bulges and irregular wear [1]. Sometimes to a certain extent, stone trapping might even lead to puncture of tires due to sharp edge of the stone structure. The five main elements of the tire tread's pattern consist of the grooves (longitudinal/lateral), tread blocks, sips, cross slots and ribs [2]. Among these few main components of the tire, stones are most found trapped in the groove section of the tire.

\footnotetext{
*Corresponding author: peixuan.ku@taylors.edu.my
} 
There are various factors that affect the performance of the tire. These factors include the design of tire tread pattern (groove type), inflation pressure, tire load and mechanical properties of material. Muniandy et al. [3] found that an increment in inflation pressure by $50 \%$ will decrease the actual contact area by $17 \%$ while an increase of tire load by $50 \%$ will increase the actual contact area by $42 \%$. Fwa et al. [4] had identified that an increase in groove depth from $1 \mathrm{~mm}$ to $9.8 \mathrm{~mm}$ could reduce the hydroplaning rate by $9.8 \%$. Besides the groove depth, the groove shape also plays an important role whereby hydroplaning rate can be reduced by an increase of $\mathrm{V}$-cut groove angle of up to 90 degrees. Hydroplaning is defined when a vehicle starts to slide uncontrollably due to tires encountering more water than the tread can displace and it most commonly occurs by speeding on a wet road. From another similar study, Kumar et al. [5] had also identified that the hydroplaning speed can be reduced by 1.25 times through increasing the tire inflation pressure from $110 \mathrm{kPa}$ to $165.5 \mathrm{kPa}$. Apart from that, Sreeraj et al. [6] had found that the wear rate of the tire increases with inflation pressure and material with high Young's modulus and density. Meanwhile, Chang et al. [7] had identified that wear rate increases with slip rate and mileage while the maximum value of the wear depth is found to be on the edge of the tread pattern. In relation to determining the wear and tear, elastic strain which is the significance of wear behaviour was found to be a more appropriate parameter to determine the wear resistance instead of material property such as the hardness alone [8]. According to a similar previous study, it was observed that the elastic equivalent stress increases with time whereby higher maximum equivalent elastic strain indicates that the tire's wear and tear is high [9]. Moreover, Wu et al. [10] found that friction coefficient is greatly influence by tire tread patterns while the dry road surface shows a greater friction coefficient value compared to the wet road surface.

Based on previous researches, it can be concluded that these studies conducted were focusing mainly on the tire tread pattern affecting the stiffness, contact area and pressure, hydroplaning rate, wear rate and friction coefficient. However, there were lack of studies that relate to the stone trapping mechanism and how the stone trapping could affect the performance of the tires. Hence, this research aims to provide an insight on how stone trapping in tire tread could have an influence on the safety of road users and lifespan of the tire.This brings upon to the objectives of this study which is to simulate stone trapping performance under various tire tread pattern geometry and to assess the effect of stone trapping has on the tire performance under different road conditions. ANSYS finite element analysis (FEA) method was used to conduct the tire inflation and steady state rolling analysis to evaluate how stone trapping reacts on different tire tread patterns under different road conditions.

\section{Methodology}

\subsection{D CAD modelling}

The geometry of the commercial vehicle tires namely the symmetrical, asymmetrical and direction tires were created using SolidWorks software as shown in Fig. 1. The specifications of the tire were based on a 15-inch tire (205/60R15) as demonstrated in Table 1. A simple road surface measuring at a width of $300 \mathrm{~mm}$ and $1000 \mathrm{~mm}$ in length is also created using this software to act as a fixed support for the tire model.

Fusion360 software was used to create 3 irregular stones model of different shapes and sizes. To obtain the stones of different design, a shape of quad ball form was first created with the identified dimensions. The span face of this shape was set at 16 units so each form can be edited in a translational manner until it mimics the shape of a typical road stones. The drawing of these stone models was limit to the geometric specification of the tire groove 
width and depth which is $5 \mathrm{~mm}$ and $8 \mathrm{~mm}$ respectively. Thus, the stones were modelled in the range between $4.5 \mathrm{~mm}$ and $6.2 \mathrm{~mm}$ in terms of their width and height as shown in Fig. 2.

Table 1. Tire specifications.

\begin{tabular}{lc}
\hline \multicolumn{1}{c}{ Description } & Specification \\
\hline Tire width $(\mathrm{mm})$ & 205 \\
Aspect ratio & 60 \\
Height $(\mathrm{mm})$ & 123 \\
Wheel outer diameter $(\mathrm{mm})$ & 693 \\
Rim diameter $(\mathrm{mm})$ & 447 \\
Groove width $(\mathrm{mm})$ & 5 \\
Groove depth $(\mathrm{mm})$ & 8 \\
\hline
\end{tabular}

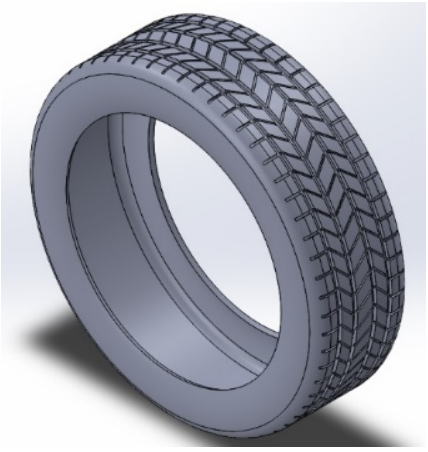

(a)

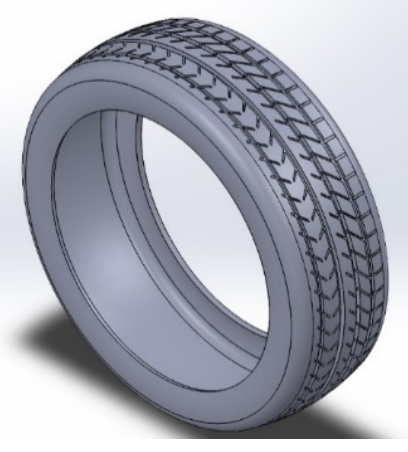

(b)

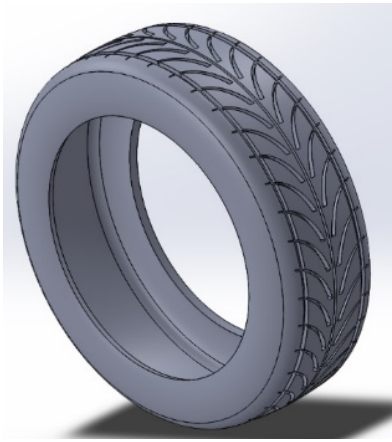

(c)

Fig. 1. Tire tread pattern of (a) symmetrical, (b) asymmetrical and (c) directional.
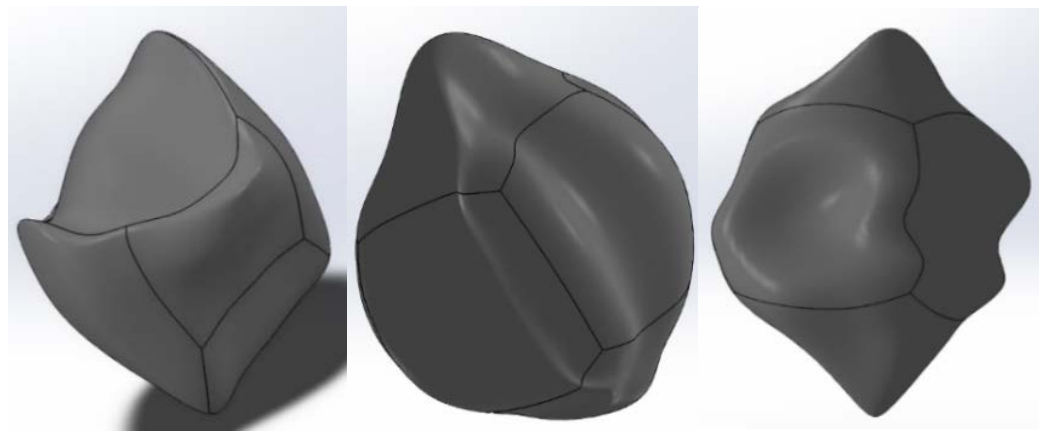

Fig. 2. 3D CAD model of the irregular stones

To obtain tire with stones trapped in its groove, the stones were assembled into the desired section of the tire's groove using SolidWorks mate and lock feature. A fixed number of 40 stones were assembled into every tread pattern. This was solely done to ensure fair comparison can be made from this study. Upon obtaining the stone trapped tire, it was then mate coincident and concentric to the vertical plane of the road surface and finally a complete stone trapped tire on a road surface was formed for simulation purpose. 


\subsection{Mesh Independency Test}

The stone trapping mechanism and performance of the tires are analyzed through finite element analysis method (FEA) using the ANSYS software as this method has proven to be a reliable approach in simulating the physical behavior of engineering designs [11]. A mesh independence test was done for each of the tire tread patterns to obtain the most suitable mesh size for the analysis. This test is first done by obtaining the mesh date from ANYS as shown in Table 2. Using the mesh data, graphs of maximum equivalent stress and total deformation against the number of elements were plotted which then proceed with the graph analyzing part. The points where the trend of the curve starts to become constant was taken and the mesh size which correspond to this point was assumed as the most appropriate mesh size for this tire tread pattern. This mesh element size is appropriate as it provides the most accurate results with the least computing time. Apart from that, the average skewness that correspond to the mesh size was also obtained to identify which column of these mesh sizes fall under based on the skewness mesh metric spectrum. From the results obtained, it was deduced that the mesh size obtained falls under the 'Very Good' and 'Good' column based on the skewness mesh metric spectrum shown in Fig. 3.

Table 2. Mesh data obtained for all tread pattern.

\begin{tabular}{lccccc}
\hline $\begin{array}{l}\text { Tire Tread } \\
\text { Pattern }\end{array}$ & Mesh size & Elements & Nodes & $\begin{array}{c}\text { Average } \\
\text { skewness }\end{array}$ & $\begin{array}{c}\text { Skewness } \\
\text { level }\end{array}$ \\
\hline Symmetrical & 0.015 & 43140 & 105383 & 0.47427 & Very Good \\
Asymmetrical & 0.020 & 58584 & 121954 & 0.76819 & Good \\
Directional & 0.020 & 44448 & 86991 & 0.49125 & Very Good \\
\hline
\end{tabular}

\begin{tabular}{|c|c|c|c|c|c|}
\hline Excellent & Very good & Good & Acceptable & Bad & Unacceptable \\
\hline $0-0.25$ & $0.25-0.50$ & $0.50-0.80$ & $0.80-0.94$ & $0.95-0.97$ & $0.98-1.00$ \\
\hline
\end{tabular}

Fig. 3. Skewness mesh metric spectrum [12].

Fig. 4 demonstrates the meshing of the tire for all tread patterns. A finer mesh was applied to the tire's contact region or the areas of interest where the equivalent stress, total deformation and elastic equivalent strain will be obtained from.

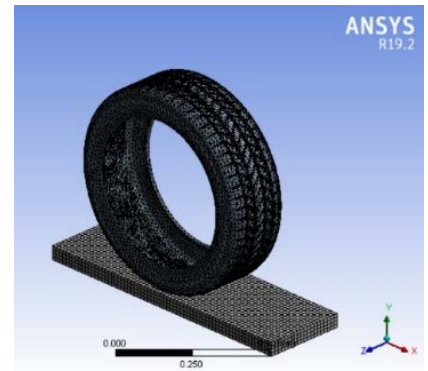

(a)

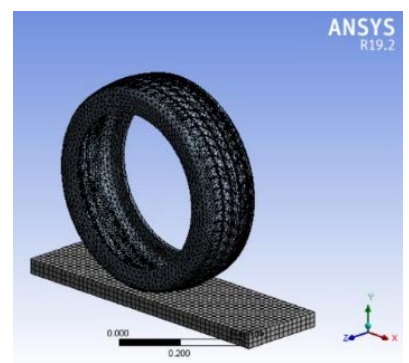

(b)

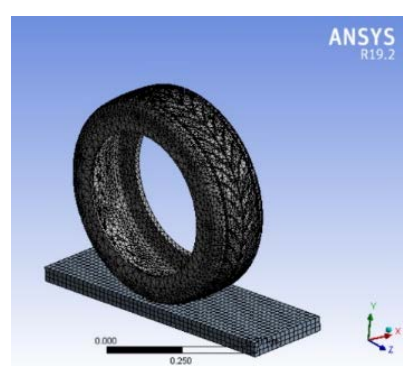

(c)

Fig. 4. Geometry meshing of (a) symmetrical tire, (b) asymmetrical tire and (c) directional tire. 


\subsection{Material selection and applying boundary condition}

The tire inflation analysis and steady state rolling analysis were conducted using ANSYS 19.1 software to evaluate how stone trapping reacts on different tread patterns as well as on wet and dry road conditions. Both non-stone trapped and stone trapped tires of all the 3 tread patterns tire had undergone these analyses to evaluate the wear and tear rate and tire's behavior. Styrene butadiene rubber and natural rubber were assigned to these tires while concrete, available in ANSYS material library was used for the stones and road surface.

The tire inflation analysis was conducted to determine the tire's behavior by identifying how different tread patterns would react when there is stone trapping. For this analysis, the tire models are subjected to the vertical force and displacement at y component so they would not rotate out of the $\mathrm{x}$ and $\mathrm{z}$ plane. A force magnitude of $2750 \mathrm{~N}$ was applied to the whole body of tire and a uniform pressure of 2 bar or $0.2 \mathrm{MPa}$ was also inflated into the tire through applying at the inner region of the tire. Lastly, a fixed support was applied to the bottom region of the road surface.

Meanwhile, the steady state rolling analysis was performed to determine the tire's wear when there is stone trapping and this analysis was analyzed in both wet and dry road condition. For this analysis, same boundary conditions were set whereby the displacement, force, fixed support and pressure were applied at the same regions mentioned above. Additional contact joints in terms of the revolute and translational were applied to the sidewall and front surface of the road respectively. This was done to allow the tire to rotate at a fixed position without rolling out from the road. The displacement set for this analysis was $100 \mathrm{~m}$ and in order to do so, the rotational velocity of the tire was fixed at $100 \mathrm{~m} / \mathrm{s}$ and the rotating period was determined at $1 \mathrm{~s}$. This principle of simple average velocity formula was used in this case to ensure the displacement set for this analysis. Furthermore, the road was made frictional where the friction coefficient was set at 0.7 to represent the dry road while 0.4 to represent the wet road [13].

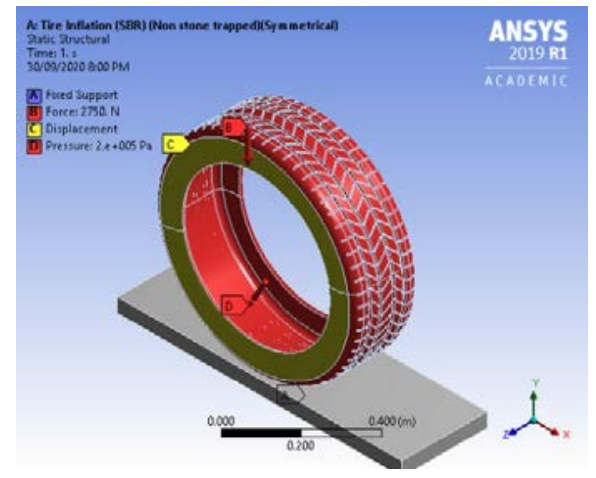

Fig. 5. Boundary condition set for the analysis.

Table 3. Material properties [6].

\begin{tabular}{lccc}
\hline \multicolumn{1}{c}{ Parameters } & $\begin{array}{c}\text { Styrene Butadiene } \\
\text { Rubber }\end{array}$ & Natural Rubber & Concrete \\
\hline Density $\left(\mathrm{kg} / \mathrm{m}^{3}\right)$ & 950 & 1100 & 2300 \\
Young's Modulus (MPa) & 10 & 6 & 30000 \\
Poisson Ratio & 0.48 & 0.49 & 0.18 \\
Tensile Yield Strength (MPa) & 24.54 & 20 & - \\
Tensile Ultimate Strength (MPa) & - & - & 5 \\
\hline
\end{tabular}




\subsection{Data Simulation}

For the tire inflation analysis, the observation on different tire tread behavior in terms of the shape deformation was done through analyzing the total deflection and Von-Mises stress. The focus of tire parts in this analysis would be the belts and sidewalls.

The steady state rolling analysis was conducted to determine the wear resistance of the tire in both wet and dry surfaces. Maximum equivalent elastic strain was obtained from this analysis to track which tread pattern has the most wear and tear regarding stone trapping. A comparison of results between non stone-trapped tire and stone trapped tire were done for each of the tread patterns to identify the relative difference in the Von-Mises stress and total deformation. The relative difference can be obtained through Eq. (1) as follows:

$$
\text { Relative difference }=\frac{\text { Stone trapped value }- \text { Non stone trapped value }}{\text { Non stone trapped value }} \times 100 \%
$$

*The stone trapped value refers to value of maximum Von-Mises stress and total deformation for stone trapped and vice versa.

Upon obtaining the relative difference of the results for all the tread patterns, these results were then compared again with one another to identify which tire tread pattern has the least and most effect on stone trapping mechanism. As for the steady state rolling analysis, same comparison was done in this analysis like the tire inflation analysis with the exception that it was compared on different road surface (wet and dry) to identify what will the impact of the friction coefficient has on stone trapping mechanism. Besides that, the identification on whether stone trapping will affect the lifespan of the tire can be deduce in this analysis as well.

\section{Results \& Discussion}

\subsection{Analysis of tire inflation}

The Von-Mises stress defines as an actual stress which involves both combined shear and tensile stress to predict a yielding of a material. Meanwhile, the total deformation can be put as a change in shape of a body which resulted from the stress applied. In this study, both components mentioned were evaluated using ANSYS where Fig. 6 and Fig. 7 demonstrate the result of this analysis.

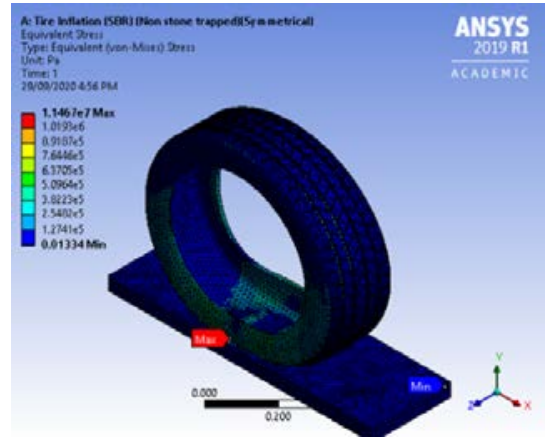

(a)

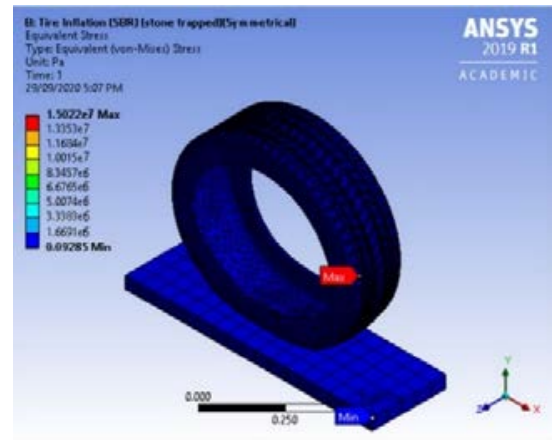

(b)

Fig. 6. Equivalent Von-Mises stress of symmetrical tire with (a) non-stone trapped and (b) stone trapped. 


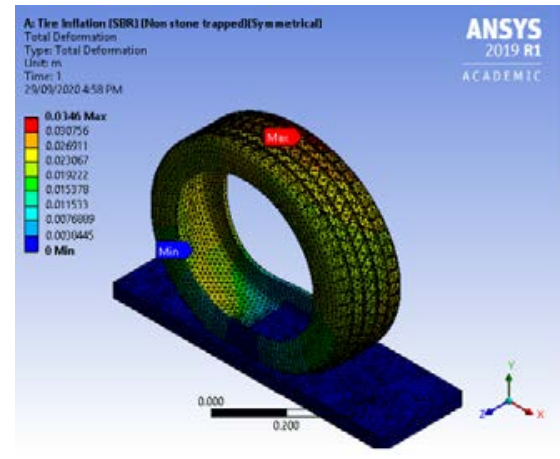

(a)

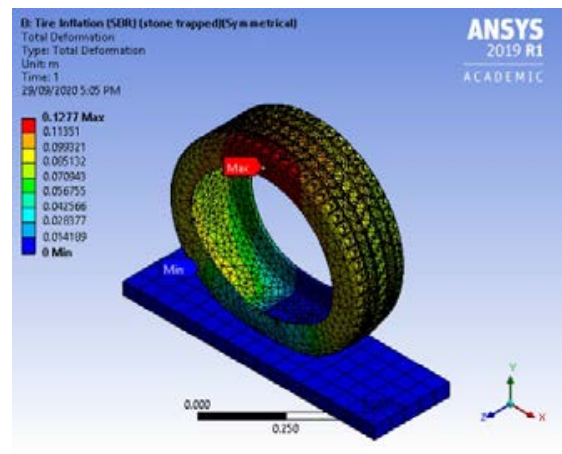

(b)

Fig. 7. Total deformation of symmetrical tire with (a) non-stone trapped and (b) stone trapped.

Table 4. Maximum equivalent Von-Mises stress and total deformation of tire tread patterns (styrene butadiene rubber).

\begin{tabular}{lcccc}
\hline \multirow{2}{*}{$\begin{array}{c}\text { Type of tread } \\
\text { pattern }\end{array}$} & $\begin{array}{c}\text { Maximum } \\
\text { Equivalent } \\
\text { Von-Mises } \\
\text { Stress, MPa }\end{array}$ & $\begin{array}{c}\text { Total } \\
\text { Deformation, } \mathbf{m}\end{array}$ & $\begin{array}{c}\text { Maximum } \\
\text { Equivalent } \\
\text { Von-Mises } \\
\text { Stress, MPa }\end{array}$ & $\begin{array}{c}\text { Total } \\
\text { Deformation, } \mathbf{m}\end{array}$ \\
\hline Symmetrical & 11.47 & 0.0346 & 15.02 & 0.1277 \\
Asymmetrical & 19.19 & 0.1435 & 24.84 & 0.3391 \\
Directional & 9.35 & 0.07457 & 13.98 & 0.1408 \\
\hline
\end{tabular}

According to Fig. 6 and Fig. 7, whereby tire inflation analysis was performed on the symmetrical tread pattern, it was observed that the equivalent Von-Mises stress and total deformation were higher when there is stone trapped. Likewise, this goes the same for the 2 other type of tread patterns, asymmetrical and directional, where the equivalent Von-Mises stress and total deformation are greater for the stone trapped (Table 4). From the results tabulated in Table 4, it is observed that the maximum equivalent Von-Mises stress ranges between 9.35 to $24.84 \mathrm{MPa}$. Similarly, a previous study conducted by Ihueze et al. [14] had also evaluated that the maximum Von-Mises stresses value were found to be at the range between 5 to $30 \mathrm{MPa}$ whereby the predominant values were located at the sidewall region.

Besides, it can also be seen that the location of the maximum stress and total deformation are acting upon the sidewalls of the tire regardless if its stone trapped or non-stone trapped. According to Spiegel and Limbrunner [15], it is understood that these stresses are developed at the sidewalls when various layers of material tend to slip with respect to one another from the force applied. Also, in this study, a maximum pressure of 2 bars or $0.2 \mathrm{MPa}$ that is inflated into the inner region of the tire has induced the sidewalls to create resisting forces to put against the inflation pressure that is acting within the sidewall of the tire. The resisting forces which compose of shear and tensile stresses are then distributed over the sidewall radially [16]. This gives a clear image of why the maximum stresses are mainly found at the sidewall of the tire. Apart from that, Chang et al. [7] had identified that the maximum value of the total deformation is found to be on the edge of the tread pattern which is proven to be the same situation for this study. 
Table 5. Maximum equivalent Von-Mises stress and total deformation of tire tread patterns (natural rubber).

\begin{tabular}{lcccc}
\hline \multirow{2}{*}{$\begin{array}{c}\text { Type of tread } \\
\text { pattern }\end{array}$} & $\begin{array}{c}\text { Maximum } \\
\text { Equivalent } \\
\text { Von-Mises } \\
\text { Stress, MPa }\end{array}$ & $\begin{array}{c}\text { Total } \\
\text { Deformation, } \mathbf{m}\end{array}$ & $\begin{array}{c}\text { Maximum } \\
\text { Equivalent } \\
\text { Von-Mises } \\
\text { Stress, MPa }\end{array}$ & $\begin{array}{c}\text { Total } \\
\text { Deformation, } \mathbf{m}\end{array}$ \\
\hline Symmetrical & 10.64 & 0.0156 & 13.18 & 0.1038 \\
Asymmetrical & 15.16 & 0.1163 & 21.52 & 0.3127 \\
Directional & 9.31 & 0.0546 & 13.21 & 0.1156 \\
\hline
\end{tabular}

Besides, this analysis was also repeated by applying different type of material to the tire to analyze how different material composition could affect the behavior of tire when there is stone trapping.

By applying natural rubber as another type of material to the tire, the maximum equivalent Von-Mises stress and total deformation are also observed to be higher when there is stone trapped in all type of tread patterns (Table 5). However, it was found that there is a slight decrease in both Von-Mises stress and total deformation as it compared with the styrene butadiene rubber (SBR) used as the applied material. This is mainly due to the material properties of the different type of rubber used whereby SBR has a higher Young's modulus than the natural rubber. Sreeraj et al. [6] had found that the wear rate of the tire increases with material with high Young's modulus because of the high contact pressure acting between the tire and the ground surface. Similar to a study conducted by Dhokey and Rane [17], it was found that the Young's Modulus correlates well with wear resistance and thus this is why the mechanical properties in the material chosen could very well affect the value of total deformation and stress in this case.

Table 6. Relative difference in Von-Mises stress and total deformation of each type of tread pattern with applied material of styrene butadiene rubber and natural rubber.

\begin{tabular}{lcccc}
\hline \multirow{2}{*}{$\begin{array}{c}\text { Type of tread } \\
\text { pattern }\end{array}$} & \multicolumn{4}{c}{ Relative difference, \% } \\
\cline { 2 - 5 } & $\begin{array}{c}\text { Styrene } \\
\text { butadiene } \\
\text { rubber }\end{array}$ & $\begin{array}{c}\text { Natural } \\
\text { rubber }\end{array}$ & $\begin{array}{c}\text { Totyrene } \\
\text { Styreformation } \\
\text { butadiene rubber }\end{array}$ & Natural rubber \\
\hline Symmetrical & 30.95 & 23.87 & 269.08 & 285.38 \\
Asymmetrical & 29.44 & 41.95 & 136.31 & 168.87 \\
Directional & 49.52 & 41.89 & 88.82 & 111.72 \\
\hline
\end{tabular}

Based on Table 6, it is observed that there is a significant relative difference in total deformation especially for the symmetrical tread pattern followed by asymmetrical and directional tread pattern regardless of any material applied to the tire. Besides that, the result also shows that the natural rubber results in a greater relative difference for all the tread patterns compared to styrene butadiene rubber.

Apart from that, it is observed that there is lesser relative difference in Von-Mises stress compared with the relative difference in total deformation. For this case, the directional tread pattern shows the greatest relative difference followed by the symmetrical and asymmetrical tread pattern. It can also be seen that the natural rubber also results in a greater relative difference but however this only applied to the asymmetrical tread pattern and not the 2 other remaining tread patterns.

It can be deduced that the directional tire would be the most ideal tread pattern since it has the least effect on the stone trapping mechanism for this case. The relative difference in 
terms of total deformation and Von-Mises stress were found to be the lowest for this tread pattern. In addition, the directional tread pattern also contributes to the lowest maximum Von-Mises stress for both non stone trapped and stone trapped despite of any material applied.

\subsection{Analysis of steady state rolling}

Steady state rolling analysis was performed in relation to determine the wear and tear of the tire. In this study, the equivalent elastic strain was evaluated where Fig. 8 and Fig. 9 demonstrates the result obtained for this analysis.

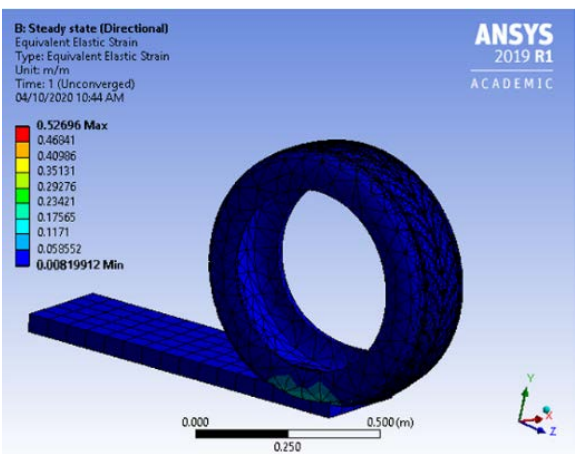

(a)

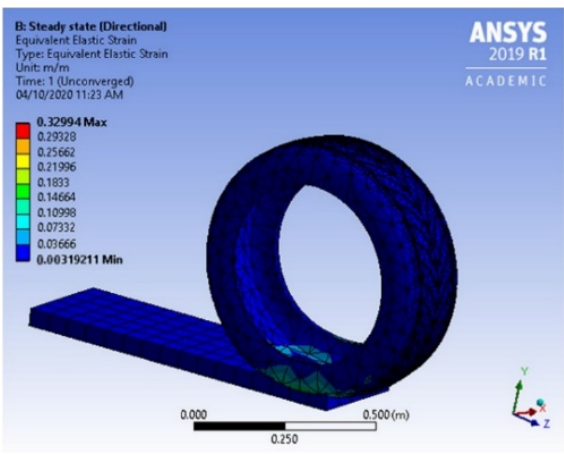

(b)

Fig. 8. Equivalent elastic strain of non-stone trapped directional tire on (a) dry road and (b) wet road.

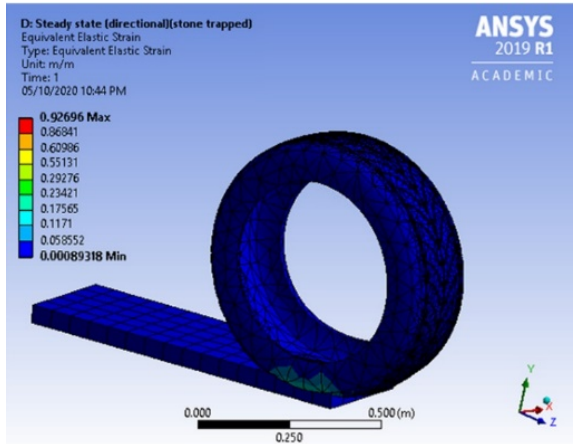

(a)

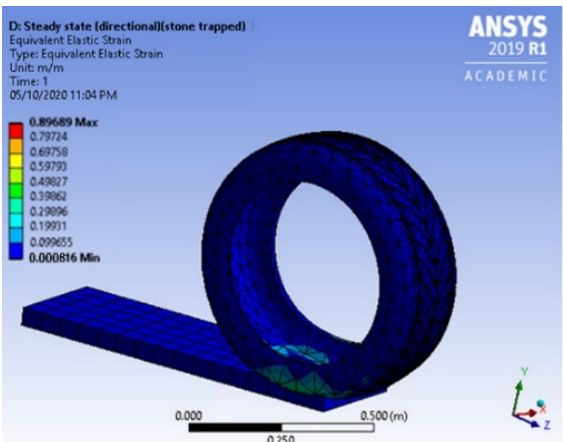

(b)

Fig. 9. Equivalent elastic strain of stone trapped directional tire on (a) dry road and (b) wet road.

According to Fig. 8 and Fig. 9, steady state rolling analysis was performed on a directional tread pattern, it is observed that the equivalent elastic strain is lower on a wet road for both cases of stone trapped and non-stone trapped. In contrast, the equivalent elastic strain reaches to a greater value on a dry road for both cases. In general, it is understood that the dry road surface would generate more friction than the wet road surface and hence tire wear will be greater on a dry road [18]. Farroni et al. [19] had also expressed that a dry road would results in a difficulty for the tire rubber to slip over the road surface which in turns leads to heat build-up in the tire. This eventually increase the tire wear and tear due to an increase of tire temperature. Apart from that, it can also be seen that the value of equivalent elastic strain doubled in the case where there is stone trapped as to compared with the non-stone trapped. 
Table 7. Maximum equivalent elastic strain of tire tread pattern.

\begin{tabular}{ccccc}
\hline \multirow{2}{*}{$\begin{array}{c}\text { Type of tread } \\
\text { pattern }\end{array}$} & \multicolumn{2}{c}{ Non stone trapped } & \multicolumn{2}{c}{ Stone trapped } \\
\cline { 2 - 5 } & \multicolumn{2}{c}{ Maximum Equivalent Elastic } & \multicolumn{2}{c}{ Maximum Equivalent Elastic } \\
& \multicolumn{2}{c}{ Strain, $\mathbf{m} \mathbf{m}$} & \multicolumn{2}{c}{ Strain, $\mathbf{m} \mathbf{m}$} \\
\cline { 2 - 5 } & Dry road, & Wet road, & Dry road, & Wet road, \\
& $\boldsymbol{\mu = 0 . 7}$ & $\boldsymbol{\mu = 0 . 4}$ & $\boldsymbol{\mu = 0 . 7}$ & $\boldsymbol{\mu = 0 . 4}$ \\
\hline Symmetrical & $8.2971 \mathrm{e}-4$ & $3.7354 \mathrm{e}-5$ & $3.5229 \mathrm{e}-3$ & $8.3142 \mathrm{e}-4$ \\
Asymmetrical & $1.6882 \mathrm{e}-4$ & $1.6793 \mathrm{e}-5$ & $4.7392 \mathrm{e}-3$ & $9.5219 \mathrm{e}-4$ \\
Directional & 0.5270 & 0.3299 & 0.9270 & 0.8969 \\
\hline
\end{tabular}

Similarly, the results obtained for the 2 other tread patterns which are the symmetrical and asymmetrical also shows that the maximum equivalent elastic strain is greater for the case where there is stone trapped and on a dry road condition (Table 7). For the case of nonstone trapped, the symmetrical tread pattern shows the lowest value of maximum equivalent elastic strain followed by the asymmetrical and directional. As for the case of stone trapped, the asymmetrical tread pattern results in the lowest value of maximum equivalent elastic strain followed by the symmetrical and directional.

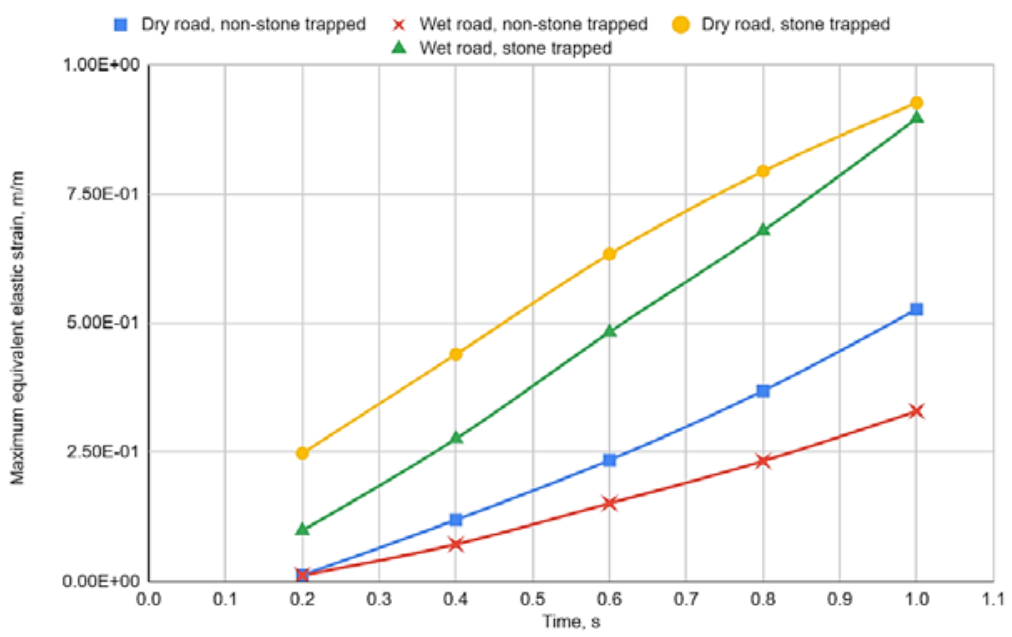

Fig. 11. Maximum equivalent elastic strain against time for directional tread pattern.

From the Fig. 11, it is observed that a good fit graph is obtained where the equivalent elastic strain increases linearly with the time interval for both cases of non-stone trapped and stone trapped. Like a previous study performed by Singhal et al. [9], a close range of equivalent elastic strain value was observed similarly to the results obtained in Table 8 for the non-stone trapped case whereby a good fit graph was also obtained.

All in all, it can be deduced that the stone trapping in tire tread pattern would have an impact on the lifespan of the tire. This is observed when there is a significant increase of the maximum equivalent elastic strain value for all type of tread patterns in the case of stone trapped as it compared to non-stone trapped. Furthermore, it can be also be deduced that the symmetrical tread pattern design is the most ideal for this case since it provides the least wear and tear for both dry and wet road condition. This tread pattern was found to have the lowest increment of maximum equivalent elastic strain from the case of non-stone trapped to stone trapped in both road condition. 


\section{Conclusion}

To summarise, this study highlights the stone trapping mechanism on commercial road tires and further emphasizes on what critical effect it has on them. In this case, this research paper analyses and compare the performance in terms of tire's behaviour and wear rate between both stone trapped and non-stone trapped tires. The parameters considered in this study includes the type of common commercial tires used in Malaysia (symmetrical, asymmetrical, directional), tire specifications, type of rubber material, inflation pressure, road condition (wet, dry), groove depth and size of stones. Both CAD modelling and simulation processes are completed using SolidWorks, Fusion360 and ANSYS 19.1 software respectively.

The results obtained from the tire inflation analysis shows that there is a significant increase in the tire's stresses and total deformation when there is stone trapped. It was also found that the directional tread design shows the least effect on the stone trapping mechanism since it contributes to the lowest maximum Von-Mises stress for both non stone trapped and stone trapped despite of any material applied.

The results obtained from the steady state rolling analysis indicates that tire's wear is higher when there is stone trapped specifically on a dry road surface as to compared to stone trapped on a wet road surface. Through this analysis, it was found that the symmetrical tread pattern design provides the least wear and tear since it has the lowest increment of maximum equivalent elastic strain from the case of non-stone trapped to stone trapped in both road condition.

All in all, this study aims to provide an insight on how stone trapping in tire tread could have an influence on the safety of road users and lifespan of the tire through the results obtained. Apart from that, this study also pursues to aid in contributing on further analysis particularly in the scope of optimizing the design of tire in any future study.

For future works relating to this study, experimental method can be involved to prove or validate the results and hypotheses of this novel study. Additional parameters like different moving average speed and other type of road conditions such as muddy or winter road surface should also be taken into consideration in this study to provide a deeper insight on this topic. Furthermore, explicit dynamic analysis can also be conducted to determine the harmonic response of the tire under stone trapping for the given boundary conditions. This can further help to optimize the tire tread pattern towards obtaining the best fit design to overcome or to reduce negative impact of stone trapping on the tire performance.

This work is supported by Taylor's School of Computer Science and Engineering for providing sufficient resources and tools.

\section{References}

1. Continental Tires. (27 April 2020). Tire damages. Available: https://www.continentaltires.com/car/tire-knowledge/tire-damage-age-repair/tire-damages.

2. Bridgestone. (28 April 2020). Tire Tread Patterns. Available: https:/www.bridgestonetire.com/tread-and-trend/tire-talk/tire-tread-patterns

3. R. Muniandy, D. Moazami, H. Hamid, S. Hassim, "Characterization of effective tire contact area for various tread patterns," Instrum. Sci. Technol., 42, pp. 15-26 (2014)

4. T. F. Fwa, S. S. Kumar, K. Anupam, G. P. Ong, "Effectiveness of tire-tread patterns in reducing the risk of hydroplaning," Transp. Res. Rec., 2094, pp. 91-102 (2009)

5. S. S. Kumar, K. Anupam, T. Scarpas, C. Kasbergen, "Study of hydroplaning risk on rolling and sliding passenger car," Procedia Soc. Behav. Sci., 53, pp. 1019-1027 (2012) 
6. R. Sreeraj, V. Sandeep, R. Gokul, P. Baskar, "Tire wear analysis using ABAQUS," Int J Innov Res Sci Eng Technol, 5, pp. 14403-14410 (2016)

7. J. Chang, H. Chenyuan, J. Xiaoxiong, "FE simulation of tire wear with complicated tread pattern," Procedia Engineering, 15, pp. 5015-5019 (2011)

8. A. Leyland, A. Matthews, "On the significance of the H/E ratio in wear control: a nanocomposite coating approach to optimised tribological behaviour," Wear, 246, pp. 1-11 (2000)

9. A. Singhal, M. S. Khidiya, D. Gautam, S. Meena, K. Gahlot, "Analysis of a tyre on different treads at same pressure and load under static conditions," Int. J. Sci. Res. Sci. Eng. Technol., 2, pp. 653-657 (2016)

10. J. Wu, Y. S. Wang, B. L. Su, Q. Liu, "Experimental and numerical studies on tire tread block friction characteristics based on a new test device," Adv. Mater. Sci. Eng., 2014, p. 816204 (2014)

11. E. Madenci, I. Guven, The finite element method and applications in engineering using ANSYS® (Springer, 2015)

12. K. Gok, S. Inal, A. Gok, E. Gulbandilar, "Comparison of effects of different screw materials in the triangle fixation of femoral neck fractures," J. Mater. Sci. Mater. Med., 28, p. 81 (2017)

13. B. N. J. Persson, U. Tartaglino, O. Albohr, E. Tosatti, "Rubber friction on wet and dry road surfaces: The sealing effect," Phys. Rev. B, 71, p. 035428 (2005)

14. C. Ihueze, C. O. Mgbemena, A. Menon, "2D static failure prediction for critical stresses of an Automobile Tire Side Walls using MATLAB PDE Toolbox," IOSR Journal of Mechanical and Civil Engineering, 11, pp. 70-76 (2014)

15. L. Spiegel, G. F. Limbrunner, Instructor's manual to accompany applied statics and strength of materials, fourth edition (Prentice Hall, 2004)

16. C. O. Mgbemena, T. E. Boye, I. Emovon, "Static analysis of a tire sidewall developed from tailored Organomodified Kaolin/Natural Rubber Vulcanizates," J. Adv. Eng. Comput., 1, pp. 106-113 (2017)

17. N. B. Dhokey, K. K. Rane, "Wear behavior and its correlation with mechanical properties of $\mathrm{TiB}_{2}$ reinforced aluminium-based composites," Adv. Tribol., 2011, p. 837469 (2011)

18. B. Ma, H.-g. Xu, Y. Chen, M.-y. Lin, "Evaluating the tire wear quantity and differences based on vehicle and road coupling method," Adv. Mech. Eng., 9(5), p. 1687814017700063 (2017)

19. F. Farroni, R. Russo, F. Timpone, "Experimental investigations on rubber friction coefficient dependence on visco-elastic characteristics, track roughness, contact force, and slide velocity," Tire Sci. Technol., 45, pp. 3-24 (2017) 